\title{
3 \\ DEVELOPMENTS IN PRIMARY EDUCATION IN SCOTLAND
}

Margaret M.Clark

\section{INTRODUCTION}

In Scotland, as in England and Wales, there have been major developments in the curriculum and in assessment in primary schools over the past ten years. The 5-14 Development Programme which was initiated in Scotland over the period 1987-93 has taken the form of a series of national guidelines, based on reports of working parties of professionals closely involved in work in the schools. The recent changes in Scotland, in contrast to England, do not represent a sharp change from previous policy. The 5-14 Programme is intended to give clarification and guidance, with a stress on balance, breadth and continuity in children's learning over the ages 5-14. The aim of the national guidelines and recommendations for assessment is to provide teachers, parents, pupils and others with a clearer statement of what schools can reasonably expect children to attain between the ages of 5 and 14. In Scotland, as in England, there was a 'child-centred report' in the 1960s, Primary Education in Scotland (SED 1965). There does not appear to have been a backlash against the report, which is often referred to as the 'Primary Memorandum', as there has been recently in England against the Plowden Report (DES 1967). Indeed, the developments in Scotland reflect many of the views expressed in the Primary Memorandum on the purpose and nature of primary education.

In this chapter a brief reminder will be given of the organisation of education in Scotland in so far as it is relevant to understanding primary education (see Chapter 1 for further information). The extent to which recent developments mirror the recommendations of the Primary Memorandum of 1965 will be considered. The national guidelines 5-14 and related assessment documents will then be discussed as far as they apply to primary schools and their links with secondary schools. Where appropriate a comparison will be made with the changes in primary education in England since 1988. Evidence of the extent to which the national guidelines appear so far to be influencing practice in primary schools in Scotland will be considered. Brief reference will be made to recent projects involving modern languages and Gaelic-medium units in primary schools. 


\section{THE STRUCTURE OF PRIMARY EDUCATION IN SCOTLAND}

The following are key features:

1 Teachers in primary schools in Scotland must be registered with the General Teaching Council (Scotland) and are required during their initial teacher training to have covered the age range 3-12, with practical experience with each age group. The approval of courses of training is jointly the responsibility of the Scottish Office and GTC.

2 Primary education in Scotland covers seven years, from 5 to 12 .

3 There is a single entry date to primary school in Scotland, namely the beginning of the school year, at which time all children enter school who will be five years of age by the end of February of that school year.

4 The teachers' contract in Scotland limits the size of classes in primary schools to 33 pupils, with an 'upper limit' of 39 and a 'maximum' of 25 in composite classes. Special schools and units have lower numbers.

5 Over 95 per cent of pupils attend education authority schools. By June 1996 there was only one self-governing primary school in Scotland receiving funding direct from central government.

6 There are many small primary schools; in some local authorities most of the primary schools have fewer than 100 pupils. There are over one hundred schools with 20 pupils or under.

\section{RECOMMENDATIONS FOR PRIMARY EDUCATION IN 1965 AND SINCE 1987: A COMPARISON}

Primary Education in Scotland (SED 1965) was prepared by a committee of teachers, college lecturers and members of Her Majesty's Inspectorate of Schools. It aimed to provide an appraisal of the best practices in primary schools and to contain valuable information and advice on methods, facilities and organisation in the classroom and the school. I have found it interesting to look back after thirty years at my annotated copy of the report and relate its recommendations to the current guidelines, as I was involved in its dissemination to both teachers in training and experienced teachers. The national guidelines for the 5-14 curriculum and assessment in Scotland and other papers from the Scottish Consultative Council on the Curriculum (SCCC) in the 1990s with regard to primary education have the following features in common with the Primary Memorandum of 1965:

The importance of continuity in a child's education; children's differing rates of development; and the importance of avoiding treating each subject as if it were a self-contained entity are all stressed.

The five curricular areas within which teaching and learning are set out within the current 5-14 Programme are similar to the areas discussed in the 
Memorandum in 1965 (in contrast to the discrete subjects within which the national curriculum is organised in England).

In the national framework set up in the 1990s there are suggested minimum percentages of time for each of these primary areas so that there is a proper balance between them. In a similar spirit to the Memorandum, time is left to the school's discretion, to allow for adjustments as children progress through the school and as individual needs arise and change.

The purposes of assessment set out show an appreciation of the continuous nature of development, the differing rates at which individual children reach these stages and the relationship of assessment to children's learning.

Problems about implementing curricular changes and providing adequate resources for small rural schools are considered.

There is a chapter in the Memorandum (SED 1965) on modern languages in the primary school; the points discussed there are relevant to current initiatives in primary schools.

In a chapter on Gaelic in the Memorandum the duty of schools in Gaelicspeaking areas not only to teach Gaelic as a subject in its own right but also to employ it as a means of instruction for Gaelic-speaking pupils in other subjects is stressed. A revival of interest in Gaelic in primary education in the last few years has been coupled with initiatives funded by the Scottish Office.

Thus recent developments in primary education in Scotland are not radically out of step with principles established over thirty years ago. This may well help to explain the more ready acceptance and implementation of the curriculum and related initiatives in Scotland in the 1990s. In England and Wales, in contrast, the national curriculum and related assessment are strikingly different from recent practice in primary education.

\section{CURRICULUM AND ASSESSMENT IN PRIMARY EDUCATION: A POLICY FOR THE 1990s}

\section{Curricular developments}

The government's wish to move towards a national curriculum, periodic national testing and greater accountability in schools is reflected in the developments over the past ten years in primary schools in Scotland, as it is in England and Wales. In 1987 a consultation paper was issued by the Secretary of State for Scotland entitled Curriculum and Assessment in Scotland: A Policy for the 90s (SED 1987), which claimed to identify a need for clearer and more structured advice on the balance between different components of the curriculum. Recognition was given, however, to curricular developments already underway for the age group 14-16. For that reason the focus for the new national guidelines was to be 5-14 (not 5-16 as in England). The consultation paper stated that national guidelines for the curriculum and for assessment in Scotland should ensure 'balance and 
breadth' under the already agreed headings of language arts, mathematics, environmental studies, expressive arts and religious education (including social and moral education). Concern was expressed to ensure not only balance and breadth, but also continuity on transfer from primary to secondary school. Thus already one can see a very different emphasis in Scotland with regard to the structure of the curriculum. In England and Wales, in contrast, the curriculum was divided into Core and other Foundation Subjects, with separate working groups to plan the curriculum within the different subject areas for the various 'Key Stages' 1-4.

In Scotland, by 1991 a series of working papers had been prepared by groups of professionals closely in touch with work in primary and secondary schools in the five following areas (related reports were also available or in preparation): English language, mathematics, environmental studies, expressive arts, and religious and moral education. After a period of consultation, national guidelines were published for each area based on the working-party reports. The workingparty reports on the various curricular areas and on assessment were preceded by a general paper subtitled The Balance of the Primary Curriculum (SED 1989), in which minimum time allocations for the curriculum areas in the primary school were given, together with a 'flexibility element'. By 1993 the guidelines in all five curricular areas for 5-14 had been published by the Scottish Office Education Department (the renamed Scottish Education Department):

In 1991:

English language (listening, talking, reading and writing). Mathematics (problem-solving and enquiry, information handling, number, money and measurement, shape, position and movement).

In 1992:

Expressive arts (including art and design, drama, music and physical education).

Religious and moral education (Christianity, other world religions and 'personal search').

In 1993:

Environmental studies (including science, social subjects, technology, health education and information technology).

A national guideline was also published in 1993 for personal and social development 5-14 (SOED 1993c).

The Structure and Balance of the Curriculum 5-14 (SOED 1993d) took account of the responses to the working paper of 1989, and developments in the Programme since then. It provides a useful overview of the Programme, intended to be helpful to schools in implementing the 5-14 curriculum. It lists the 
'attainment outcomes' and 'strands' in the guidelines listed above. The following points are stressed:

- the principles governing the curriculum 5-14 are breadth, balance, coherence, continuity and progression for all pupils;

- the importance of the five curricular areas;

- the need for consideration of cross-curricular aspects;

- the structure of each of the national guidelines is intended to encourage the development of policies by individual schools and their implementation in the classroom;

- the starting point for assessment is to be the 'planned curriculum'.

Assessment is to be considered in terms of planning, recording, reporting and evaluating. To quote: 'Through these processes teachers gather information so that they can make professional judgements about pupils' progress and communicate these to pupils and parents' (SOED 1993d: 18).

A number of important features in the planning of the curricular proposals in Scotland differ from those in England:

1 Existing committees were charged with making the recommendations for the curriculum and assessment (not, as noted earlier, new committees as in England).

2 The membership of the working parties set up by the Scottish Consultative Council on the Curriculum reflected the wide range of professionals involved in education in schools, teachers in primary schools and subject specialists, headteachers from different types and sizes of schools, advisers and directors of education, college lecturers and representatives of the profession on secondment to SCCC. On the working parties was someone with expertise in the education of children with special needs, to whose educational needs attention was able to be paid.

3 A general framework is common to all the working papers and national guidelines; these include recommendations for attainment outcomes and targets and programmes of study.

4 These guidelines, which were published after a period of consultation, appear to have retained the main recommendations of the working parties.

5 In Scotland, following the publication of each guideline the schools have been encouraged to implement the proposals, with the aim of full implementation by 1998-9, without, as in England, being faced with amendments and revisions of the curriculum and the national tests within a very short time of their introduction.

6 Working-party reports on assessment and reporting, with a focus on improving classroom assessment and partnership with parents, were being issued for consultation at the same time as the curriculum documents. 


\section{Assessment within the primary school}

In Scotland over the past ten years there have been two parallel developments in assessment.

General recommendations for assessment and reporting to parents have been linked with and built into the national guidelines; this assessment is an integral part of the national guidelines for the subject areas. Working-party reports on assessment have been followed by consultation and then national guidelines, on Assessment 5-14 (SOED 1991a) and Reporting 5-14 (SOED 1992c). Further documents to support these guidelines have been issued by SOED, including staff development packs, showing the importance accorded to the professional development of teachers in classroom assessment.

In addition to the above, there has been a programme of national tests, though in English and mathematics only. These tests were to be administered when the children had completed three years in primary school (that is, when they were eight years of age), and at the end of their primary schooling. The preparation of the national tests in Scotland was the responsibility of the Primary Assessment Unit in the Scottish Examination Board. The tests in English were to involve two tests of reading and two of writing. The reading tests were to be of comprehension, one of a narrative passage, one for information. The children were to write on a narrative and information topic and their writing was to be assessed for choice and use of language, selection and organisation of ideas and technical skills. The mathematics tests were to cover four units at a given level: problem-solving and enquiry; information handling; number, money and measurement; and shape, position and movement; these tasks also are set in different contexts. The teachers order the tests from a catalogue of tests at the level and on the topics they think appropriate for their pupils.

National testing has been controversial in Scotland, as in England and Wales. However, the teachers and parents in Scotland have succeeded in having the programme of national testing greatly modified. When the first round of national tests took place in Scotland in 1991, owing to parental and teacher opposition, only about half the children sat the tests. More flexibility as to the time of year at which the tests were to be conducted was then permitted. Subsequently the arrangements have been modified still further. The national tests form a back-up to teacher assessment and now need to be administered only when the teacher's own assessment indicates that the pupil has largely achieved the attainment at one level, not in any particular year in the primary school. Furthermore, there is reference in the documentation to the assessment of children with special educational needs as well as those for whom English is a second language. In 1992, a circular was issued confirming the revised arrangements, and stating that an individual pupil's performance in tests is to be communicated to the pupil and the parent. In short, league tables will not be compiled comparing pupil with pupil, or school with school on the basis of the testing. Indeed, with the present structure of the testing, and the tests themselves, no such comparisons would be 
possible. Thus, the national test data are used as a confirmation of teachers' professional judgement of the level attained in English and mathematics based on a wide range of classroom evidence. There is little evidence yet of the extent to which the teachers are indeed using the national tests within the revised, more flexible arrangements.

Attention has now turned to diagnostic assessment and the preparation of materials to assist teachers in making diagnostic assessment within the key areas of English, mathematics and science, under the general general title Taking a Closer Look. The Diagnostic Procedures project was funded by the Scottish Office Education Department and the Scottish Council for Research in Education, and the guidelines have been developed in collaboration with teachers. The project team and advisory committee were composed of staff from SCRE and colleges of education and from members of Her Majesty's Inspectorate. The booklets and related packages which link closely with the curricular developments within the 5-14 Programme are illustrated with examples from the classroom. They were made available free to all schools with the aim of helping teachers assess pupils' understanding and progress, and identify appropriate next steps (SCRE 1995).

\section{DEVELOPMENTS IN PRIMARY EDUCATION IN ENGLAND: SOME CONTRASTS}

Those familiar with the development of the national curriculum in England will appreciate how different are the curricular and assessment guidelines recommended for primary education in Scotland. In England subject committees were established whose members were chosen by the Secretary of State for Education. Each subject committee worked in isolation, leading inevitably to an overloading of the curriculum, particularly for primary schools at Key Stage 1. It is thus no surprise that radical revisions and a drastic slimming down should have proved essential. A crucial element within the development of the national curriculum in England has been the assessment at the end of each Key Stage (that is, in the primary school, when the children are about 7 and 11 years of age). The way that the assessment has developed, with an increasing focus on externally devised Standard Assessment Tasks (SATs), has resulted in the assessment driving the curriculum, possibly in inappropriate ways. Claims from teachers in England of pressures of work resulting from the national testing at the end of Key Stage 2 have led to external marking of scripts. The assessment is externally imposed at a particular point in time; the teachers are themselves not involved in the actual assessment of the scripts, receiving only the marked scripts without any diagnostic scoring on them; thus at most they can challenge the final mark. Recent documents from the School Curriculum and Assessment Authority (SCAA) are beginning to exhibit a greater commitment to recognising teachers in England as professionals and teacher assessment as fundamental to good teaching. 
It would be naive to suggest that the plans for assessment formulated in Scotland in the 1980s and early 1990s were not politically driven, or that they were free from political interference; the same government was in power in Scotland over that period as in England and Wales. However, the criticisms made by the former chairmen of the committees in England and Wales could not so readily be levelled at the developments in Scotland. As noted earlier, national testing in Scotland in the primary school was only ever planned for English and mathematics and was to take place when the children had completed three years in school and were eight plus years of age; and league tables of the results of individual schools were not published. Furthermore, as a consequence of opposition even these plans have been modified. While teachers in Scottish primary schools have had to face the pressures of implementing the new curricular proposals, their colleagues in England have had to face the following additional pressures:

- publications by the former chairmen of the key committees on the curriculum and assessment criticising the way their reports have been interpreted;

- the greater emphasis on SATs rather than teacher assessment;

- the inclusion of assessment of mathematics and science for seven-year-olds as well as English, which left teachers with less time to spend on English, because of their insecurity in the other areas (science assessment at Key Stage 1 has now been dropped);

- attempts to compare schools' performance in the form of league tables, based on SATs, without any allowance for the very different starting points of the children, and in some schools, particularly in the inner cities, the large number of children for whom English is a second language. This last point has added to the political agenda in England the issue of 'value-added' assessment and currently, a proposal for compulsory Baseline Assessment of all children on entry to primary school.

In Scotland, in contrast to England, the national guideline for English language seems to give greater recognition to the diversity of culture and language within our community, and to a desire to foster respect for this in young children (see SOED 1991b). While reports on primary education by HMIs in Scotland have expressed concern at some aspects of language and writing, as was noted earlier, other aspects have received praise. There is concern about standards of literacy in Scotland and whether these are high enough, with a number of intervention projects underway with the aim of improving standards. There is also anxiety as to whether such projects are vulnerable with the current level of funding and the replacement of the large Regions by smaller councils. However, the surveys of literacy conducted within the Assessment of Achievement Programme indicate that over the past twenty years, at least until 1992, there has been no decline in standards of literacy in primary schools. At the end of primary education (in Primary 7) there has been no change in either reading or writing; in Primary 4, 
there has been no change in reading and a slight fall in writing (Commission on Scottish Education 1996).

In England, English has been a high-profile subject politically, and one which has over recent years been subjected to a number of revisions. Claims have been made of falling standards; the methods employed to teach reading have been criticised, with demands for an increased emphasis on 'phonics'; claims have been made that there should be greater emphasis on spelling, grammar and punctuation, and on Standard English from early in the primary school. The curriculum proposed has been revised, and under threat of further revision over the ensuing years, as have been the assessment procedures. Those teaching English in primary schools in England have met not only with pressures from the proposals themselves and the national tests, the first when children are barely seven years of age. They have also been faced with frequent revisions. Research projects funded to analyse the effects of the changes were either barely completed, or the results were not yet widely available, before revisions to the curriculum and its assessment were considered. A recent review of the national curriculum and its assessment recommended that it be slimmed down, and that there should be no further changes for a period of five years.

In Scotland, the structure of the national guidelines, the fact that they cover broad areas and the fact that continuous assessment and improving teachers' assessment have been a major focus throughout the developments during 1990s have led to a more positive reaction by professionals to the developments. The extent to which these documents have so far influenced practice in primary schools in Scotland will be considered in the following section.

\section{AN EVALUATION OF THE 5-14 PROGRAMME}

The working parties planning the 5-14 Programme were set up from 1989; the first guidelines, those in English language and mathematics, were published in 1991; the final guidelines were published in 1993, and it is intended that the full 5-14 Programme will be in place in all areas of the curriculum by 1998-9. An independent evaluation of the implementation of the 5-14 Development Programme was funded by the Scottish Office Education and Industry Department (SOEID) between 1991 and 1995, with projects based at the Scottish Council for Research in Education, the University of Edinburgh, the University of Strathclyde and Northern College. A further two-year study is being sponsored by SOEID. The programme is set in context, and the main findings of the evaluation are reported in Four Years of Change in Education 5-14 (Harlen 1996); a fuller report on the findings of the evaluation of the implementation in primary schools is to be found in 5-14 in the Primary School: The First Four Years (Malcolm and Byrne 1996).

With regard to the curriculum, the researchers found that in primary schools initially implementation of the English language and mathematics guidelines had dominated the attention of the schools. However, by 1994 teachers appeared to 
have become familiar with the content and terminology of these and there was evidence of positive feelings towards them. As yet little progress had been made in implementation of the guidelines in the areas of religious and moral education, the expressive arts or environmental studies. The guidelines on environmental studies were regarded as helpful, making clear what was expected in this area and in planning to ensure that all aspects were covered. Headteachers were reported as regarding the guidelines as useful to ensure consistency of direction among staff and to help with staff development. A number of the teachers who were interviewed thought that 'their pupils were benefiting from a broader range of learning experiences, from the new emphasis on oral and problem-solving skills, and from a more consistent, continuous learning experience' (Malcolm and Byrne 1996:vi).

With regard to assessment, the researchers found that teachers tended to regard the specific guidelines on assessment as helpful. They appreciated the link in the guidelines between teaching and learning, and the opporturtity they provided for reflection on assessment. During the period of the research the plans for the national testing in English and mathematics had to be modified as a consequence of opposition of teachers and parents. Many of those interviewed did not see the value of these tests and thought that they would merely encourage teaching to the test; some felt that they did not assess children's knowledge adequately.

In addition to balance and breadth in the curriculum, continuity was stressed as important in the 5-14 Programme. The researchers found some evidence of improved liaison between primary and nursery schools, helped, it was thought, by the 5-14 Programme. Primary-school staff expressed some satisfaction with links with secondary schools, though they felt that the contacts needed to be more orientated towards the curriculum. As will be seen in the following chapter there is limited evidence so far of impact of the 5-14 Programme on secondary schools, or that it has improved the continuity of children's learning when they move from primary to secondary school.

The evaluation reported here covers the early years of the implementation of the 5-14 Programme, mainly of the first two curricular guidelines to be introduced and the beginning of use of the assessment and reporting guidelines. Changes in the national testing announced at the end of 1992 were only beginning to be put into practice as the final data were collected. It will therefore be of interest to see what emerges from the evaluation in the years 1995-7. It is yet to be seen whether the changes so far will be sustained and what the impact will be on primary education in Scotland of the whole programme.

\section{GAELIC-MEDIUM PRIMARY SCHOOLS}

According to the 1991 census only 1.4 per cent of the population in Scotland over three years of age speak, read or write Gaelic. The largest concentrations are in the Western Isles, Highland and Strathclyde Regions; the remaining speakers are scattered throughout Scotland, with the largest single concentration in Edinburgh. 
However, it is only within the last ten years that education in Scotland through the medium of Gaelic in primary schools has shown a rapid increase, with support from the Scottish Office and Regional authorities. By 1996-7 there were 1,587 children in Gaelic-medium units in primary schools in Scotland. Many of the units are in small rural schools with composite classes; however, there are also units in Aberdeen, Edinburgh and Glasgow. For the first few years in primary school the curriculum may be delivered entirely through Gaelic; in the following years English will then be introduced gradually, with the aim that by the end of primary education the children will have equal fluency in Gaelic and English. Gaelic-medium education in Scotland is not confined to Gaelic speakers, or those whose parents are Gaelic speakers; a child's attendance is a matter of parental choice. There has been a high level of support from parents whose children have been experiencing Gaelic-medium education. The 5-14 national guidelines are the basis for the education in these units as in other primary schools in Scotland. There is now a national guideline 5-14 for Gaelic, in English and in Gaelic, like the other reports, based on the recommendations of a working party; it parallels the report on English language 5-14 (SOED 1993b).

The Scottish Office has in recent years supported a range of initiatives in education (including Gaelic-medium units, resources, teacher education, broadcasting, the preparation of resources, and research), with grants to support Gaelic increasing dramatically over the last ten years. In April 1996 the Secretary of State for Scotland announced a further initiative with commitment until 1998, claiming that there has been impressive progress in developing Gaelic education in the past ten years, with good-quality education in the Gaelic-medium units. Research is currently funded by the Scottish Office to study the comparative attainment levels in Gaelic- and English-medium schools (due to be reported in 1999). A number of reports of relevance to Gaelicmedium teaching in primary schools have been published recently by the Leirsinn Research Centre on the Isle of Skye - on the use of Gaelic television programmes, on the critical skills needed for teaching in Gaelic-medium units, and on teacher training for Gaelicmedium education.

\section{MODERN LANGUAGES IN THE PRIMARY SCHOOL}

In recent years there have been national and Regional projects in many parts of Scotland involving the introduction of modern languages into primary schools; current plans are to extend this to all primary schools. The first phase started in 1989, with six secondary schools, each with a number of associated primary schools. In total the national pilot projects involved 12 secondary schools and 76 primary schools, covering four languages, with by 1993 over 4,000 pupils. An initiative by Strathclyde Region included a further 24 secondary schools and 133 primary schools. Most projects were in either French or German; one was in Italian and another in Spanish. In 1992 the Secretary of State announced that over the next five years a foreign language would be introduced into every primary 
school in Scotland. In the pilot projects secondary teachers visited associated primary schools and worked with their primary school colleagues. However, with the expansion of the provision the main burden will fall on primary teachers.

There is a general feeling that the pilot projects have been successful, particularly in promoting a favourable attitude to foreign languages. There is so far limited evidence on the longer-term effects on attainment in modern languages when pupils transfer to secondary school. A report by HM Inspectorate on the introduction of French into primary schools in Scotland in the 1960s noted that there was a lack of continuity on transition to secondary school and that many primary teachers lacked sufficient competence in the language. A number of issues still need to be resolved in this current venture if it is not to fail as did the earlier one-including whether there will be sufficient primary-school teachers with the necessary qualifications to provide the main input and whether they will be able to sustain such a venture in addition to the pressures involved with the full implementation of the 5-14 Programme. Attempts are being made to ensure that courses in modem languages are available for primary teachers and that there are sufficient resources. There is now more evidence on the value of bilingual education, and of commencing a second language at an early age. The relevance of mastery of at least one European language for employment in the European Community is also likely to give added impetus to projects such as these. (Further information on the research is available from the Scottish Centre for Information on Language Teaching and Research at the University of Stirling.)

\section{STANDARDS AND QUALITY IN SCOTTISH PRIMARY SCHOOLS}

Schools in Scotland are inspected by HM Inspectors (not by OFSTED as in England). Their programme of independent inspection evaluates and reports on the quality of education and the arrangements made by schools for assuring quality. Standards and Quality in Scottish Schools 1992-95 (HMI 1996) assesses how well schools are performing in key aspects of their work across the threeyear-period 1992-95. Scotland is now several years into an initiative in which schools are encouraged to take responsibility for their own quality assurance by evaluating their performance and by making the necessary changes.

The HMI report states that staff development is a strong feature in almost all primary schools. Most teachers are reported to be good at explaining and questioning and making their instructions and expectations clear to pupils, and at using varied teaching methods and providing well-chosen learning activities. Most pupils in primary schools are said to be industrious, well motivated and responsive to their teachers. Praise is given for 'the ethos' in primary schools: it is described as very good or good in over 90 per cent of schools. (See Chapter 8 for a fuller discussion of these issues.)

There is evidence from the HMI report that schools are beginning to implement the 5-14 Programme. However, there is still some way to go before it 
is fully implemented in all the main areas of the curriculum. It should be remembered, however, that the target is for that to happen by 1998-9 (and these inspections covered the years 1992-5).

The climate within which recent curricular and assessment initiatives in primary schools have developed is perhaps best summed up in a recent publication from the Scottish CCC, Teaching for Effective Learning (SCCC 1996), which immediately on publication won glowing tributes from teachers in Scotland, and overseas, according to a report in the Times Educational Supplement Scotland (see TES Scotland, 20 September 1996:4). It is claimed that in the publication the Council has deliberately avoided prescriptive approaches. To quote:

This paper is an attempt to act in partnership with teachers, to focus our joint professional enquiry upon the most important processes taking place in our schools - teaching and learning.... The reader will find in this paper no ringing endorsement of any one single best way to teach. The paper, and indeed CCC's whole initiative in this field, is at pains to recognise that teaching is a complex, difficult and challenging task, and that there are no easy answers. It is, however, an optimistic paper, premised upon the professional commitment of teachers to their vocation.

(SCCC 1996:iii)

\section{REFERENCES}

Commission on Scottish Education (1996) Learning to Succeed in Scotland: A Radical Look at Education Today and a Strategy for the Future, Edinburgh: The Commission on Scottish Education.

DES (1967) Children and their Primary Schools, London: HMSO (the Plowden Report). Harlen, W. (1996) Four Years of Change in Education 5-14, Edinburgh: SCRE.

HMI (1996) Standards and Quality in Scottish Schools 1992-95, Edinburgh: Audit Unit, SOEID.

Malcolm, H. and Byrne, M. (1996) 5-14 in the Primary School: The First Four Years, Edinburgh: SCRE.

SCCC (1996) Teaching for Effective Learning, Dundee: SCCC.

SCRE (1995) Taking a Closer Look: Education 5-14 Diagnostic Procedures, Edinburgh: SCRE. Key Ideas in Diagnostic Assessment Taking a Closer Look at ReadingTaking a Closer Look at WritingTaking a Closer Look at NumberTaking a Closer Look at Information HandlingTaking a Closer Look at Science

SED (1965) Primary Education in Scotland, Edinburgh: HMSO (the Primary Memorandum).

(1987) Curriculum and Assessment in Scotland: A Policy for the 90s, A Consultation Paper, Edinburgh: SED.

(1989) Curriculum and Assessment in Scotland: A Policy for the 90's Paper 1, A Working Paper: The Balance of the Primary Curriculum, Edinburgh: SED. 
SOED Curriculum and Assessment in Scotland, National Guidelines: SOED (1991a) Assessment 5-14, Edinburgh: HMSO.

(1991b) English Language 5-14, Edinburgh: HMSO.

(1991c) Mathematics 5-14, Edinburgh: HMSO.

(1992a) Expressive Arts 5-14, Edinburgh: HMSO.

(1992b) Religious and Moral Education 5-14, Edinburgh: HMSO.

(1992c) Reporting 5-14, Edinburgh: HMSO.

(1993a) Environmental Studies 5-14, Edinburgh: HMSO.

(1993b) Gaelic 5-14, Edinburgh: HMSO.

(1993c) Personal and Social Development 5-14, Edinburgh: HMSO.

(1993d) The Structure and Balance of the Curriculum 5-14, Edinburgh: HMSO. 